\title{
Archéologie, histoire et anthropologie de la presqu'île de La Hague
}

\section{Cyril Marcigny et Vincent Carpentier}

\section{(2) OpenEdition \\ Journals}

\section{Édition électronique}

URL : https://journals.openedition.org/adlfi/3827

ISSN : 2114-0502

\section{Éditeur}

Ministère de la Culture

Référence électronique

Cyril Marcigny, Vincent Carpentier, « Archéologie, histoire et anthropologie de la presqu'île de La

Hague » [notice archéologique], ADLFI. Archéologie de la France - Informations [En ligne], Normandie, mis en ligne le 01 mars 2009, consulté le 22 juin 2021. URL : http://journals.openedition.org/adlfi/3827

Ce document a été généré automatiquement le 22 juin 2021.

(c) ministère de la Culture et de la Communication, CNRS 


\title{
Archéologie, histoire et anthropologie de la presqu'île de La Hague
}

\author{
Cyril Marcigny et Vincent Carpentier
}

Date de l'opération : 2009 (PC)

1 Cette dernière année d'activité du PCR a été principalement consacrée aux temps historiques. Un bilan documentaire a donc été dressé sur les époques antiques et médiévales permettant de faire un point sur les très rares données disponibles.

2 Pour l'époque antique, on sait encore trop peu de choses. En 56 avant J.-C., les légions romaines ont vaincu la tribu locale des Unelles, basée à Corialloou Coriovallo-toponyme encore non localisé, peut-être Cherbourg, dont l'interprétation a donné lieu à de nombreuses hypothèses plutôt vaines, quoi qu'il en soit très représentative du contenu de la littérature historisante relative à la Hague depuis le XIX ${ }^{\mathrm{e}} \mathrm{s}$. Il en va de même pour le tracé des voies présumées romaines mais dont aucune preuve tangible n'a été mise en avant depuis le temps de de Gerville, comme de l'hypothétique «camp romain » situé par la tradition à Jobourg où des traces de villas gallo-romaines auraient également été identifiées : un «camp » de plus dans les inventaires régionaux dont la réalité historique est fort susceptible d'être tout autre que « romaine »...

Malgré ces incertitudes tenaces, si l'on s'en tient aux données concrètes de l'archéologie, il n'existe aucune raison de considérer la Hague comme un désert galloromain. En tout premier lieu parce qu'on y trouve, autant qu'en d'autres pays bocagers de la province normande, des mentions dispersées mais nombreuses de tuiles, de monnaies, de céramiques gallo-romaines qui attestent de l'occupation de l'espace au cours des premiers siècles de notre ère. D'autre part, les études environnementales conduites sur les tourbes anciennes de l'«Anse Saint-Martin» et de la «Mare de Vauville » dans le cadre du PCR ont révélé une activité humaine et son impact sur la végétation au cours de l'Antiquité. En revanche, les modalités de cette occupation nous échappent encore très largement. Eu égard aux limites de l'information, il n'est guère 
souhaitable de relayer davantage les interprétations hasardeuses relatives à ces supposés villas, hameaux ou autres agglomérations, itinéraires et sanctuaires galloromains dont au final, le caractère très hypothétique a masqué durablement les réalités du peuplement local depuis bientôt deux siècles. Que nous reste-t-il, après avoir écarté d'emblée les matériaux incertains ? Deux sites archéologiques, surtout, doivent retenir aujourd'hui l'attention des antiquisants.

Il s'agit tout d'abord d'un habitat encore mal cerné, peut-être une authentique agglomération, situé dans le prolongement du site portuaire d'Urville-Nacqueville, occupé au cours de l'âge du Fer. En retrait des vestiges protohistoriques ont en effet été découverts divers témoins d'occupation remontant aux premiers siècles de notre ère, urne cinéraire, monnaies romaines (dont une émission de Domitien, 51-96), tessons d'amphores vinaires Dressel 1B caractéristiques des importations maritimes de la fin du $\mathrm{I}^{\mathrm{er}} \mathrm{s}$. av. J.-C. En l'état des connaissances, on serait donc enclin à supposer l'existence d'un site du Haut-Empire à Urville-Nacqueville, dont l'occupation se situerait dans le prolongement de celle du site laténien en cours d'étude depuis de nombreuses années. Les vestiges gallo-romains seraient positionnés plus haut sur le rivage, probablement en raison de la remontée du niveau marin qui intervient au cours du second âge du Fer.

Le second site archéologique important de la Hague gallo-romaine est celui du «sanctuaire» de Digulleville, fruit de la découverte fortuite survenue en 1822 d'un dépôt de bronzes votifs tout à fait exceptionnel. Celui-ci est constitué d'une petite statuette de vénus en terre blanche, d'une patère en terre cuite et d'une hache de fer recouverte de plaques de cuivre. L'ensemble, conservé au musée Emmanuel Liais, est caractéristique des enfouissements cultuels gallo-romains du Haut-Empire. Cet assemblage pourrait traduire l'existence à Digulleville d'un sanctuaire consacré à des divinités gallo-romaines. Cette hypothèse n'est toutefois pas vérifiée à ce jour, et l'on sait aussi que de tels dépôts peuvent avoir été formés au sein d'occupations profanes telles que des villas ou des fermes, souvent dotées de parties cultuelles et/ou funéraires plus ou moins développées, voire pourquoi pas, à l'écart des zones habitées.

6 L'occupation de la Hague au cours du Moyen Âge n'est guère mieux connue que pour l'Antiquité. L'information paléovégétale extraite des tourbières de l'«Anse SaintMartin » et de la « Mare de Vauville » confirme bien cependant la présence humaine au cours du haut Moyen Âge. Le paysage de la Hague, en particulier la lande, se fixe au cours de cette période et offre une grande similitude, au XVI ${ }^{\mathrm{e}} \mathrm{s}$., avec celui que l'on connaît aujourd'hui. Cette forme paysagère va de pair avec un habitat très dispersé dont l'organisation contemporaine perpétue la tradition fort ancienne. Elle intègre également de larges surfaces boisées, qui naguère étaient vraisemblablement beaucoup plus étendues qu'aujourd'hui.

7 En marge des témoins archéologiques, rares ou inexistants, on dénombre une proportion notable de « fossiles linguistiques » en rapport avec le peuplement médiéval de la région. Beaucoup de toponymes de la Hague dénotent ainsi une influence germanique, qu'il est parfois délicat d'attribuer définitivement aux Vikings ou à leurs prédécesseurs saxons, tant les langages de ces peuples sont apparentés et construits sur des racines communes.

Quoi qu'il en soit, cet espace se distinguait surtout, du point de vue des ressources qu'il offrait, par l'exploitation de sites portuaires en rapport avec l'économie maritime au sens large (navigation, pêche, chasse baleinière, etc.) et par la présence de larges pans de forêt. Il semble bien d'ailleurs que la Hague soit longtemps restée une terre de forêt, 
ce qui éclaire dans une certaine mesure les difficultés que rencontre l'identification d'un peuplement fugace et dispersé, surtout organisé le long des côtes. On remarque en effet que la plupart des églises anciennes de la Hague se répartissent à proximité des côtes, géographie qui reflète nécessairement celle des habitats médiévaux associés aux lieux de culte.

En dehors des villages encore occupés de nos jours, dont l'église atteste clairement par sa dédicace et/ou son architecture les origines médiévales, il existe assurément dans la Hague plusieurs hameaux et villages désertés remontant au Moyen Âge classique et tardif (XII ${ }^{\mathrm{e}} \mathrm{s}$ - $\mathrm{XV}^{\mathrm{e}} \mathrm{s}$.). Certains d'entre eux se trouvent ensevelis sous les dunes et de fait, sont vraisemblablement très bien conservés. L'un de ces gisements est connu par une série de découvertes survenues dans les mielles de Biville, en limite de la Hague. Un autre habitat déserté médiéval, qui a fait l'objet d'une fouille conduite par Alain Huet (AFAN), a été mis au jour à $200 \mathrm{~m}$ du château de Beaumont-Hague. Il s'agit ici d'un groupement de maisons dont l'occupation remonte aux XII ${ }^{e}$ s.-XIV ${ }^{e}$ s., offrant la particularité d'être directement adossé au rempart du Hague-Dike. En l'état des données, ces habitats remontent au second Moyen Âge, époque au cours de laquelle s'est fixé le modèle de peuplement dispersé qui prévaut encore aujourd'hui dans la Hague. En marge des fermes isolées, beaucoup des « villages-rues » visibles aujourd'hui dans l'ensemble du Cotentin trouvent vraisemblablement leur origine dans le cours des $\mathrm{XI}^{\mathrm{e}}$ s.-XII ${ }^{\mathrm{e}}$ s., époque marquée par un net accroissement démographique.

Les rares témoins funéraires remontant au Moyen Âge contribuent à peine à enrichir cette image générale du peuplement médiéval. Le cas de la nécropole du « Hameau de la Mer ", à Siouville-Hague, qui fut rapidement fouillée au début des années soixante par Bernard Édeine (CNRS ), est particulièrement intéressant car il démontre qu'un certain nombre de sites, a fortiori d'habitats, ont été détruits par la mer depuis le haut Moyen Âge. Des attestations similaires peuvent être recensées sur l'ensemble des côtes de la Manche, où l'on dénombre également des légendes récurrentes parlant d'églises englouties... De plus, bien que cette nécropole date vraisemblablement de l'époque mérovingienne, il n'est pas sans intérêt de noter un certain nombre d'indices d'une occupation gallo-romaine antérieure aux vestiges funéraires. De tels cas de continuité furent probablement aussi fréquents dans la Hague qu'ailleurs en Normandie et il y a tout lieu de croire que la plupart des villages actuels ont des origines bien plus anciennes que l'époque viking. Malgré cela, le mythe d'une «terre viking» demeure tenace à propos de la Hague, en dépit du fait qu'aucune trace concrète de la présence scandinave n'y ait encore été clairement retrouvée.

11 Ce dernier volet des recherches sur la Hague clôt les travaux du PCR débuté il y a maintenant quatre ans. À cette occasion, une exposition accompagnée d'un ouvrage est programmée pour l'année 2010. Ce dernier reprendra l'ensemble des travaux menés sur le territoire de la Hague et fera le bilan de cette expérience d'étude dans la longue durée d'un territoire régional. Le travail documentaire mené sur la Hague ne va pas pour autant s'achever avec la fin du PCR puisque les données acquises et leurs études vont alimenter les thématiques développées dans le cadre de l'UMR 6566-CReAA H (universités de Rennes, Nantes, CNRS et MCC). Les travaux de terrains se poursuivront aussi de manière ponctuelle.

12 (Fig. $\mathrm{n}^{\circ} 1$ : Le dépôt de Digulleville : lithographie de Langlumé, Société des Antiquaires de Normandie, 1827-28.) et (Fig. $\mathrm{n}^{\circ} 2$ : Digulleville : statuette en bronze gallo-romaine) 


\section{ANNEXES}

Fig. $n^{\circ} 1$ : Le dépôt de Digulleville : lithographie de Langlumé, Société des Antiquaires de Normandie, 1827- 28.

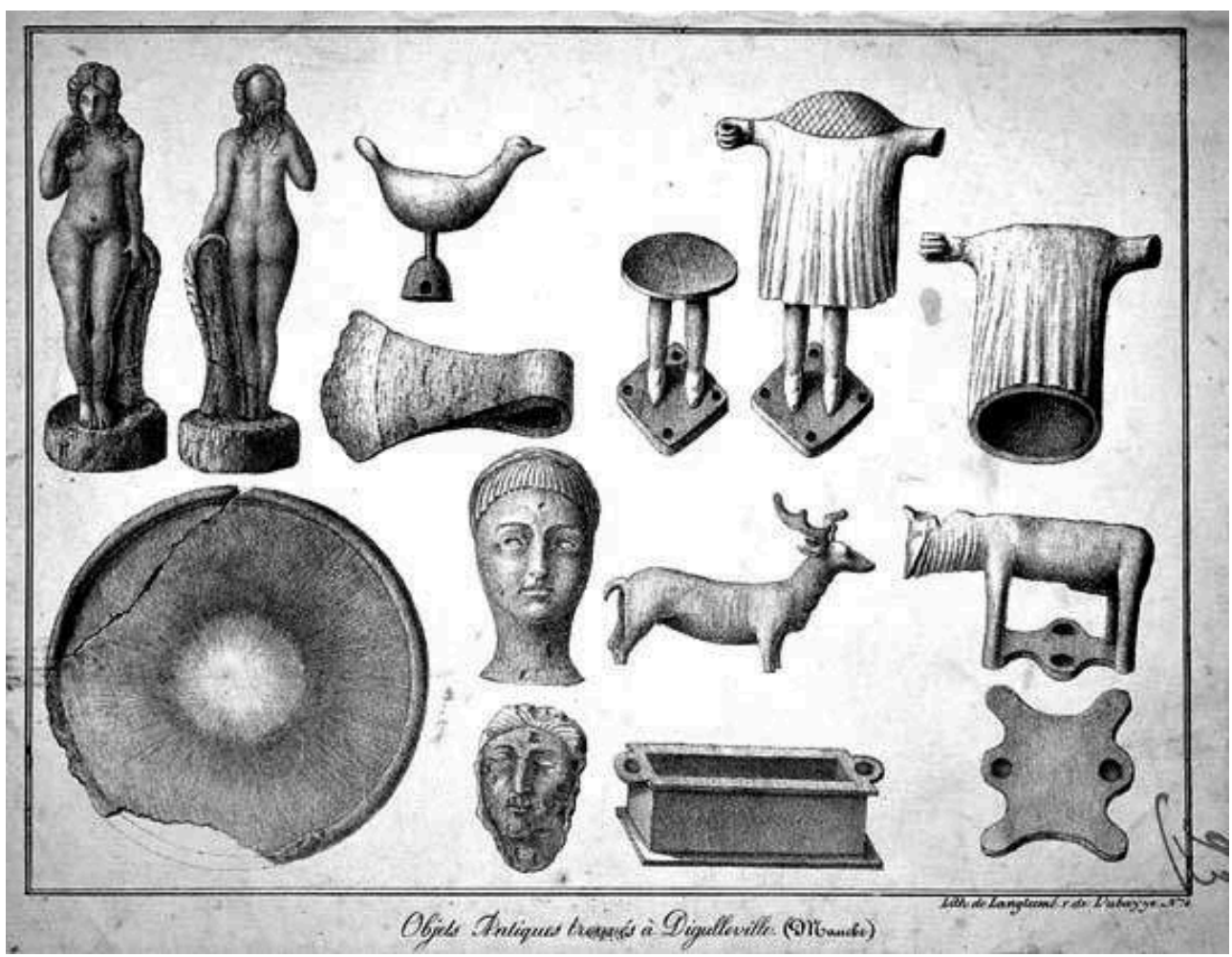

Société des Antiquaires de Normandie (2009) 
Fig. $\mathrm{n}^{\circ} 2$ : Digulleville : statuette en bronze gallo-romaine

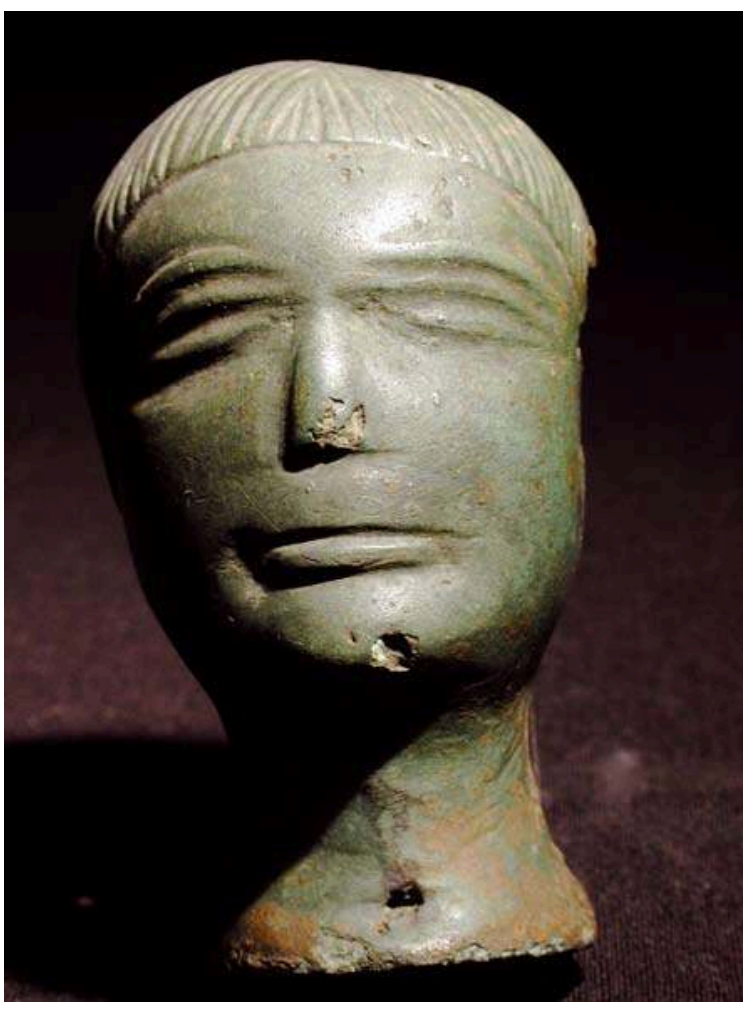

Auteur(s) : Yvon, J.-M.. Crédits : Yvon, J.-M. (2009)

\section{AUTEURS}

CYRIL MARCIGNY

INRAP

\section{VINCENT CARPENTIER}

INRAP 